\title{
Modeling of the CIGRE Low Voltage Test Distribution Network and the Development of Appropriate Controllers
}

\author{
Ghullam Mustafa Bhutto ${ }^{\mathrm{a}, \mathrm{b} *}$, Birgitte Bak-Jensen ${ }^{\mathrm{a}}$, Pukar Mahat ${ }^{\mathrm{a}}$ \\ ${ }^{a}$ Department of Energy Technology, Aalborg University, Pontoppidanstræde 101, Aalborg 9220, Denmark and \\ ${ }^{b}$ Quaid-E Awam University of Engg. Sciences \& Technology, Nawabshah 67450, Pakistan
}

\begin{abstract}
The fluctuating nature of some of the Distributed Generation (DG) sources can cause power quality related problems like power frequency oscillations, voltage fluctuations etc. In future, the DG penetration is expected to increase and hence this requires some control actions to deal with the power quality issues. The main focus of this paper is on development of controllers for a distribution system with different DG's and especially development of a Photovoltaic (PV) controller using a Static Compensator (STATCOM) controller and on modeling of a Battery Storage System (BSS) also based on a STATCOM controller. The control system is tested in the distribution test network set up by CIGRE. The new approach of the PV controller is done in such a way that it can control AC and DC voltage of the PV converter during dynamic conditions. The battery controller is also developed in such a way that it can control its charge/discharge rate and also the reactive power flow through the lines in order to improve the power factor. Simulation results shows that the controllers are able achieve a good power quality in the test grid.
\end{abstract}

Keywords: Wind turbine generator, photovoltaic, voltage source converter, static compensator, battery energy storage system, energy storage equipped STATCOM, state of charge.

\section{Introduction}

DG technology and especially renewable energy sources have played a vital role in the modern power industry due to environmental and cost benefits. The important benefits of renewable based DGs are reduced $\mathrm{CO}_{2}$ emission, reduced operational cost as almost no fuel is used for their operation and less transmission and distribution losses [1]- [3].

The intermittent and uncontrolled nature of the renewable energy sources cause problems with the quality of the power. This quality related problems include disturbances in the voltage, oscillations in power flow through the lines etc. The disturbance in the voltage can cause the disconnection of the sensitive equipment and may lead to huge economical loss due to the damaged products. Most of DGs such as Wind power, Photovoltaic etc. employ VSCs for their operation. The inverters are very sensitive to voltage disturbances. A disturbance in the voltage can cause disconnection of the inverters from the grid that leads to the loss of energy. Due to this reason the role of Custom Power Controllers (i.e. the power electronics based controllers used in distribution network) is increasing day by day. Some of the issues concerning DG have been proposed in [4]-[6].

The main focus of this paper is on development of a PV controller by using a STATCOM controller and on modeling of Battery Storage System (BSS) based on STATCOM controller. The introduction of the LV distribution network will be presented in the end of this section, the modeling of wind turbine generators (WTG) which are attached to the LV network will be given in section 2, and modeling of PV solar systems and battery storages including its control set up will be presented in sections 3 and 4 ,

\footnotetext{
* Manuscript received July 20, 2012; revised August 22, 2012.

Corresponding author. Tel.: +45-9940-9715; E-mail address: gmu@et.aau.dk, gmustafabhutto@yahoo.com
} 
respectively. The simulation results and finally the conclusion of the paper will be presented in sections 5 and 6, respectively.

As mentioned, a test distribution network set up by CIGRE comprising of WTG and PV solar generation units, as well as energy storages and unbalanced loads has been chosen for the study. The single line diagram of this distribution system is shown in Fig. 1.

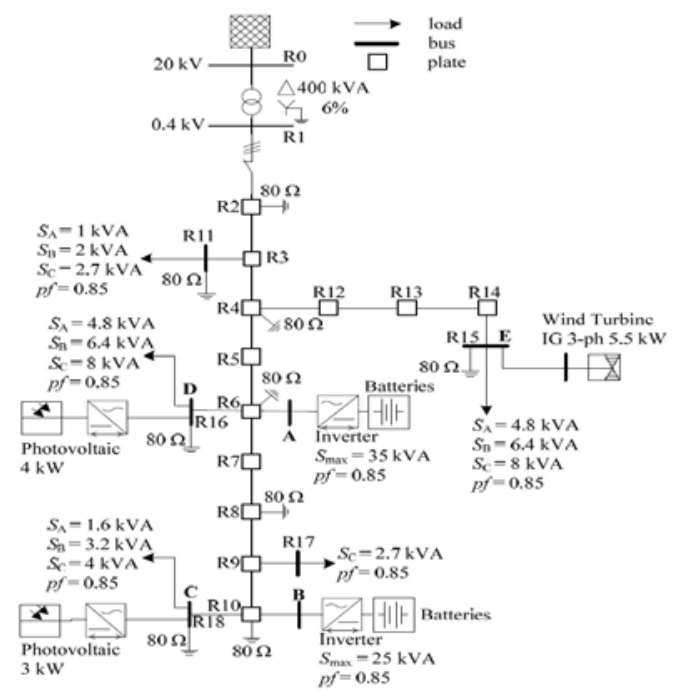

Fig.1. CIGRE distribution system test network [7]

In this network there are two PV solar generation units of $3 \mathrm{~kW}$ and $4 \mathrm{~kW}$ connected at bus $\mathrm{C}$ and $\mathrm{D}$ respectively. There is one fixed-pitch fixed speed wind turbine generator of $5.5 \mathrm{~kW}$ connected at bus $\mathrm{E}$. The WTG is operated close to unity power factor with the use of a shunt capacitor. There are two batteries connected at bus A and at bus $\mathrm{B}$. The unbalanced loads are aggregated at the $0.4 \mathrm{kV}$ voltage levels and are connected at bus C, bus D, bus E, bus 11 and bus R17. The detailed data concerning bus bars, cables/lines and loads is given in [7].DIgSILENT Power factory 14.0 has been used to model the system. The standard built-in models available in the DIgSILENT library for different electrical components have been used and new models are developed for the controllers.

\section{Modeling of Wind Turbine Generator}

During implementation of the wind turbine model in DIgSILENT, different built-in models are used for the wind turbine components, e.g. generator and capacitor. The procedures of modeling the WTG are available in various literatures [8]-[10]. The WTG is modeled according to [11] as a fixed pitch and fixed speed wind turbine in this case.

A simplified block diagram of WT system comprising a measurement file 'ElmFile' for the stochastic wind speed is shown in Fig. 2 in DIgSILENT. The turbine model uses the stochastic wind speed as an input and produces the output signal 'Pwind' (i.e. Power available in the wind). It is the input of the shaft model which generates aerodynamic torque in the shaft and thereby producing $P_{W T}$ (i.e. power from wind turbine to generator or the mechanical power)

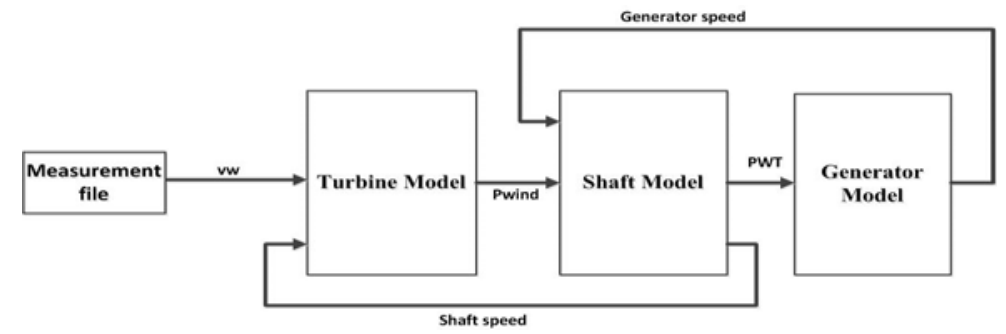

Fig.2. A simplified block of wind turbine system 


\section{Modeling of PV Generator System}

The PV solar units used in this network are operated as STATCOMs and thereby named PVSTATCOM. The controller of the PV-STATCOM is used to regulate the voltage of the distribution network. This kind of controller is being developed in the university lab of Sarnia, Canada for a $10 \mathrm{~kW}$ PV system [12]. As the power output of the PV is current dependent, the solar cell can be modelled as a dc-current source [13].As the power output of the PV cell is DC, a VSC is used to convert DC power into AC power. The built-in model of a PWM AC/DC converter is used for the VSC.

A cascade controller is used for control of the VSC. It is comprised of an outer controller and an inner controller [14]. The selection of the outer controllers depends on the application. Here STATCOM controllers for the PV applications are used for the voltage regulation. They comprise of two outer controllers (i.e. AC and DC voltage controllers). The outer controllers are basically PI controllers that are used to eliminate errors [15]. They produce the reference $d$ and q currents for the inner current controllers by comparing actual and reference signals. The inner controllers are the controllers which receives the current reference values from the outer controllers. In general, they should be very fast as compared to the outer controllers in order to achieve system stability. The procedure of modeling the control system for the PV-STATCOM in DIgSILENT is described with the help of a block diagram as shown in Fig. 3 [16].

The STATCOM controller is used to control the dc-link voltage as well as the voltage across the point of common coupling (i.e. AC bus of the corresponding VSC). The measured AC and DC voltages are sent to the voltage controllers (i.e. AC voltage controller and DC voltage controller) that are represented by the voltage controller block in Fig. 3. Both controllers are acting as outer controllers which produce d and q currents references for the inner current controllers.

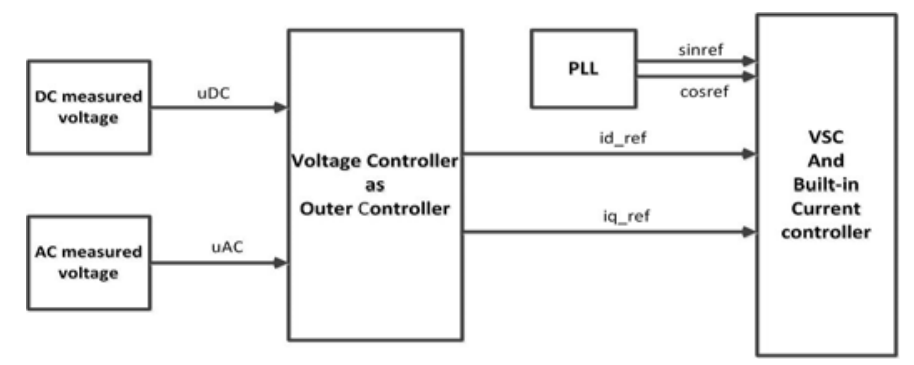

Fig.3. The block diagram of the STATCOM controller for PV solar system [16]

The current controllers (i.e. one for id_ref and other for iq_ref coming from the voltage controller) are built-in on the VSC. The three phase currents are measured from the grid and are transformed from 3phase to $\alpha \beta$ and from $\alpha \beta$ to dq coordinates by using a Phase Lock Loop (PLL) transformation angle [11]. With chosen PLL [17], the d-component of current vector becomes active current component (d-current) and $q$-component becomes reactive current component (q-current). The actual currents $i_{d q}$ and the reference currents $i_{d q}^{*}$ are compared and the differences of the currents (error) are sent to the respective PI controllers of the built-in current controllers. The output of the PI controller is reference voltage $u^{*}(t)$. This reference is sent to the PWM block which sets the switching pattern for the transistors used in the converter and decides its duty cycle.

\section{Modeling of Battery Storage System}

The Battery Energy Storage System (BESS) is incorporated with STATCOM named as BESSSTATCOM or E-STATCOM, which has both active and reactive power controllability. The BESSSTATCOM is modeled using a Thevenin equivalent representation of the Lithium ion battery and is shown in Fig. 4 [18] and [19]. The specification of a single cell of lithium ion battery is taken from [20]. The built-in model of an infinite DC voltage source is used for modeling of the BESS in DIgSILENT power factory 14.0 [21]. 


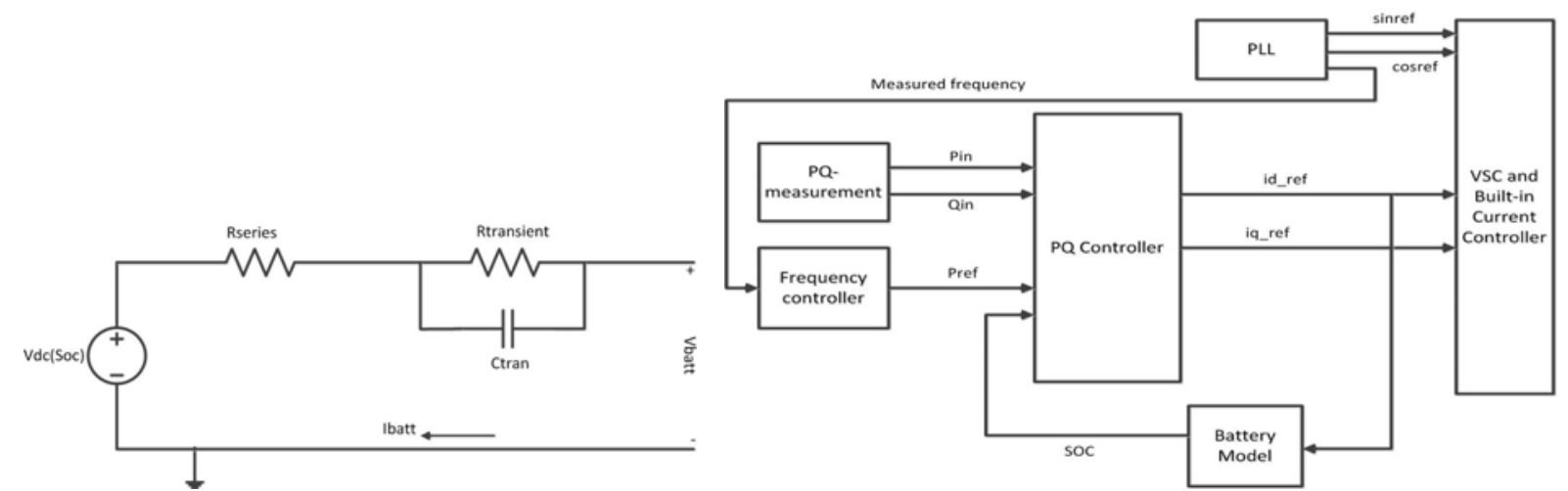

Fig.4. Electrical model of the Lithium ion battery [18] and [19]

Fig.5. Block diagram of the battery storage controller
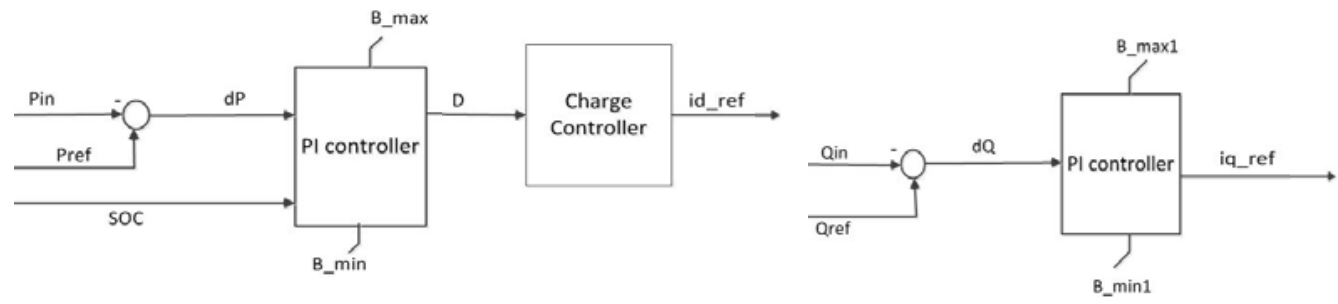

Fig. 6. PQ controller for BESS

As the power output of the battery is DC, an inverter is used to convert DC power into AC power. In order to control the charge/discharge rate of the battery, it is necessary to develop its controller. The block diagram of the control system of battery storage is shown in Fig. 5.

Two outer controllers (i.e. frequency controller and PQ-controllers) are used in this case. The frequency controller receives the reference frequency 'Fref' as its input which is supplied by a PLL. This controller compares measured and reference frequency and sends the error signals to a PI controller in order to generate $P_{\text {ref }}$.

The PQ controller is used to control charge/discharge rate of the battery and the flow of the reactive power through the lines. It also controls the flow of the reactive power through the lines. The PQcontroller in this case has measured active and reactive powers (i.e. $P_{i n}$ and $Q_{i n}$ ), reactive power reference 'Qref', Active power reference 'Pref' supplied by the frequency controller and State of Charge 'SOC' supplied by the battery model as its inputs. The PQ controller is shown in Fig. 6. Comparison of measured and reference active and reactive powers are done and the differences are sent to the respective PI controllers which produce the active and reactive currents references. The PI controller receiving 'dP' and 'soc' as its inputs is designed in such a way that if there is mismatch between measured and reference active powers, the PI controller should generate the missing signal ' $D$ ' in order to make the error signal equal to zero and if the state of charge of battery is equal to $20 \%$ or $95 \%$, the output signal ' $D$ ' of the controller should be zero. This is in order to avoid damage of the battery and to preserve battery life and thus, the SOC is limited within 20-95\% [19]. The limits (i.e. B_max and B_min) have been set in this PI controller in order to model the battery for obtaining the desired amount of the power. The output ' $D$ ' of the PI controller is sent to the charge controller which controls the current in and out of the battery and decides it's charging and discharging rate.

The battery model is shown in Fig. 7. The current in or out of the PQ controller is integrated in order to give a relative charge 'Ch' which when added or subtracted (based on charging or discharging mode) to the initial charge ' $C h_{i}$ ' in ampere-hours, gives the total charge ' $\mathrm{ChT}$ ' of a battery as shown in equation1.

$$
C h T=C h_{i}+\int_{i_{\min }}^{i_{\max }}\left(I_{\text {batt }}\right) \cdot d t
$$

This quantity is further normalized to the battery capacity so that the state of charge lies between 20 and $95 \%$. A lookup table is used for finding battery state of charge from open circuit voltage. The resultant 
battery voltage $\left(V_{\text {batt }}\right)$ is obtained by combining series resistance voltage drop $\left(V_{\text {series }}\right)$ and equivalent transient voltage response $\left(V_{\text {transient }}\right)$ with the open circuit voltage $\left(V_{o c}\right)$ as seen in equation 2.

$$
V_{\text {batt }}=V_{o c}+V_{\text {transient }}+V_{\text {series }}
$$

To get power output (Pbatt) of battery, the battery current $\left(I_{\text {batt }}\right)$ and the battery resultant voltage $\left(V_{\text {batt }}\right)$ is multiplied as seen in equation 3.

$$
P_{\text {batt }}=V_{\text {batt }} I_{\text {batt }}
$$

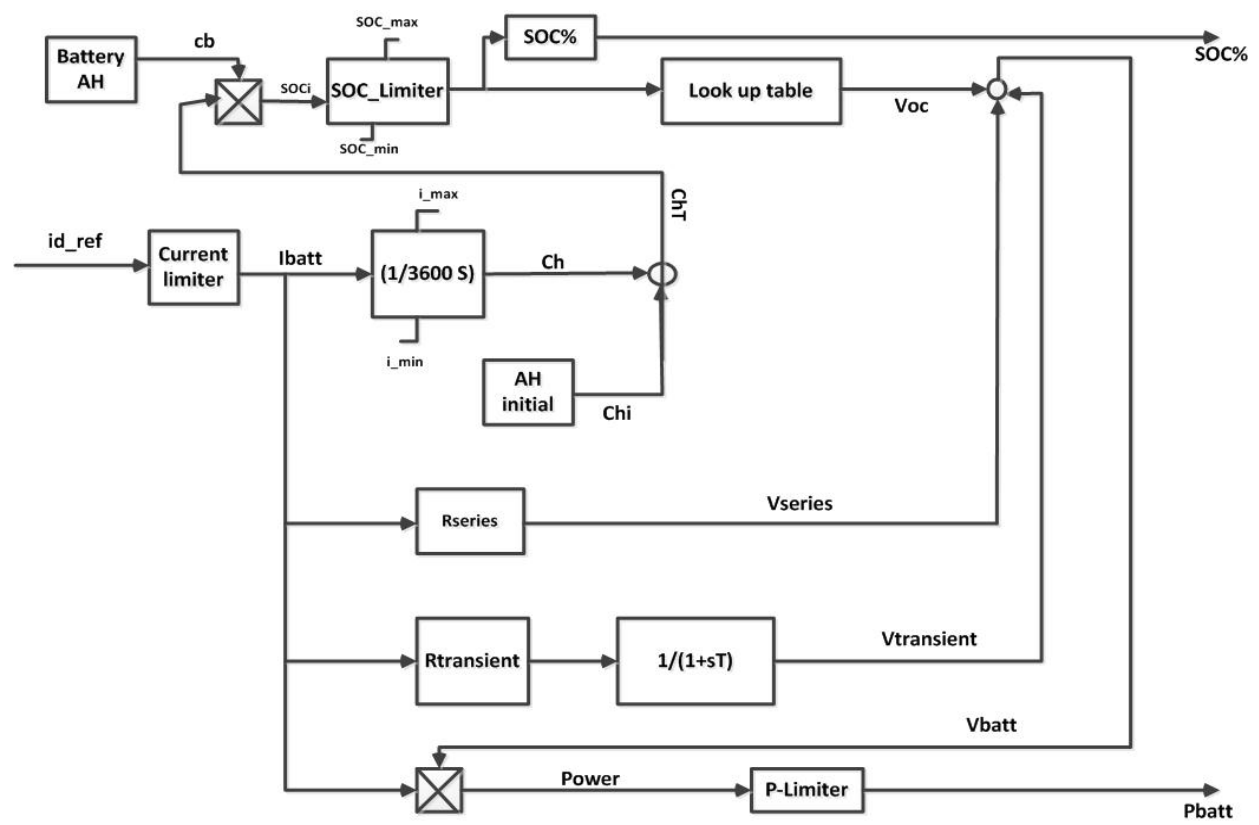

Fig. 7. The block diagram of battery model

\section{Simulation Results}

In order to verify the performance of the controllers used in the network, simulation results are presented in the case of some events applied on the network.

At $30 \mathrm{~s}$, the output power of the PV system 2 is reduced in order to simulate the reduction in the solar radiation. The power output of PV2 is shown in Fig. 8. Initially, PV2 is producing full power (i.e. $4 \mathrm{~kW}$ ). Due to clouds the power of the PV2 is reduced to $0.4 \mathrm{~kW}$ at $30 \mathrm{~s}$. As the power output of PV2 decreases, AC and DC bus voltage also decreases. The STATCOM controller is controlling the voltage in very short duration. The voltage at DC bus and AC bus of PV2 converter is shown in Fig. 9.

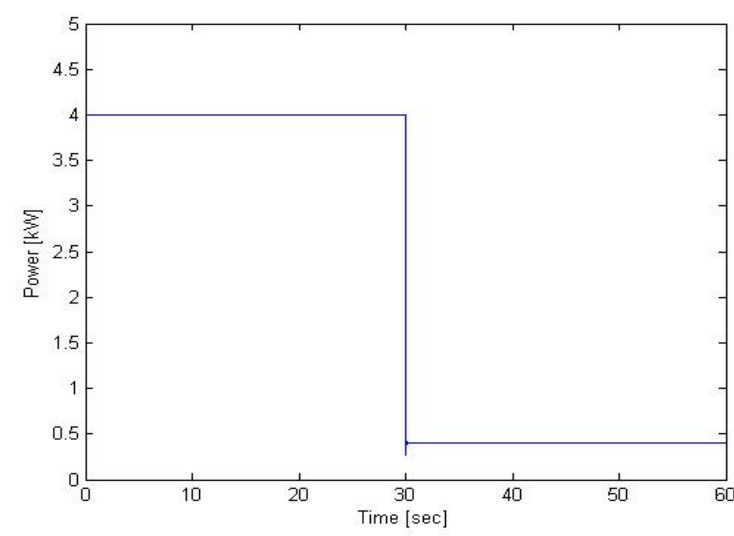

Fig. 8. Power delivered by PV2

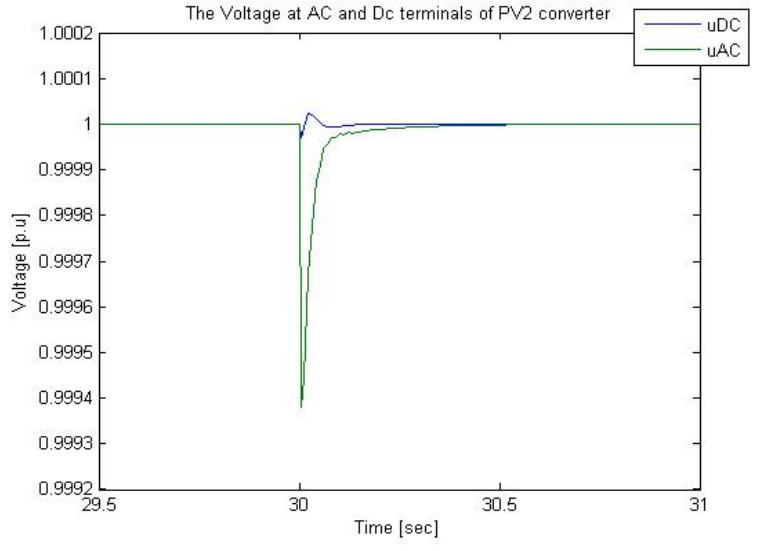

Fig. 9. Vltage at AC and DC terminals of PV2 converter 
At the same time the grid is delivering power to charge the batteries. The PQ controller is charging the batteries at different $\mathrm{C}$ rates. The plots of currents flowing from the grid to charge the battery used at bus $A$ at $1 \mathrm{C}$ and $1 / 2 \mathrm{C}$ rates are shown in Fig. 10. When battery is charged up to the specified limits, the flow of current from the grid as shown in Fig. 9 is decreasing to zero.

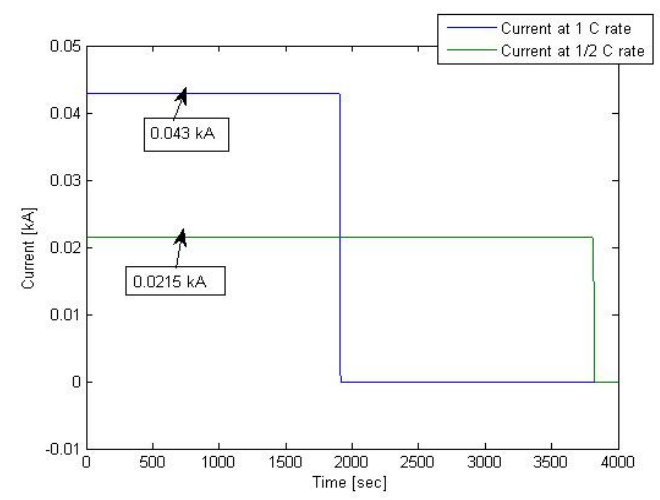

Fig.10. Currents to charge the battery at two different rates

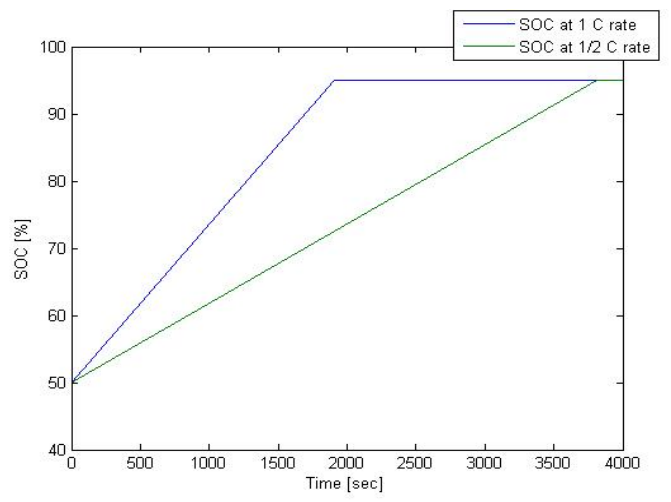

Fig.11. Sate of charge of the battery at two different rates

The plots for the battery SOC at two different rates (i.e. $1 \mathrm{C}$ and $1 / 2 \mathrm{C}$ rates) are shown in Fig. 11. The grid is delivering $43 \mathrm{~A}$ to charge the battery connected at bus $\mathrm{A}$ at $1 \mathrm{C}$ rate. In this condition battery is charging faster. The battery is drawing half of the rated current at $1 / 2 \mathrm{C}$ rate and is charging slower. It takes more time to charge up to the desired limit as shown in Fig. 11. The PQ controller is also used to control the reactive power through the lines and improve the power factor. The reactive flowing through line R8A is shown in Fig. 12.

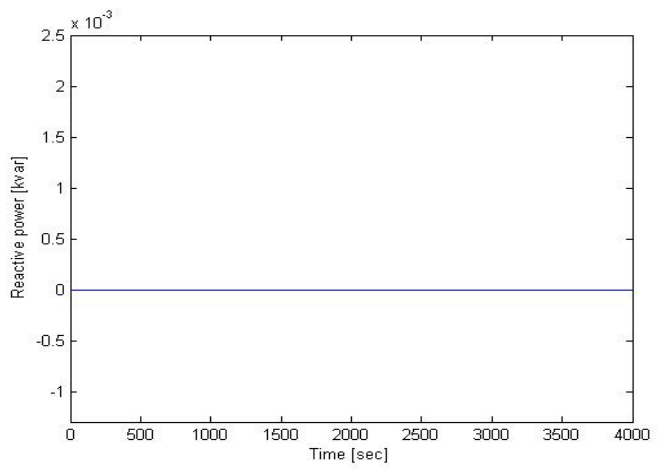

Fig.12. Reactive power through line R8-A

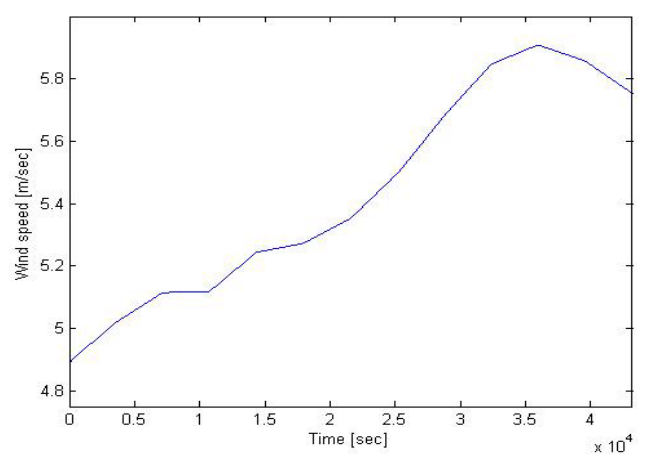

Fig.13. Wind variations of January 1, 2009 for East Denmark

Next the controllers are to be verified with e wind power fluctuations, fluctuations in the power output of a PV system and also load changes for the unbalanced load. The wind speed data of $1^{\text {st }}$ January 2009 for East Denmark given by DTU wind energy is used, as shown in Fig. 13 and the power output of a PV system is assumed for the sunny day. The fluctuations in the power output of WTG and PV2 is shown in Fig. 14. The load variation for all three phases at bus D is shown in Fig. 15.

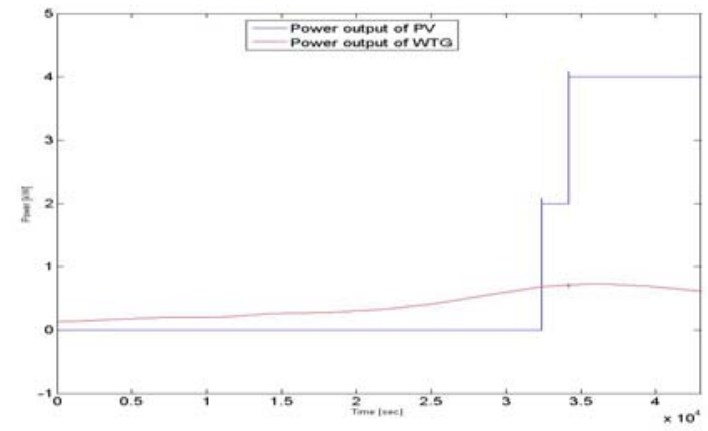

Fig. 14. The power output of PV2 and WTG

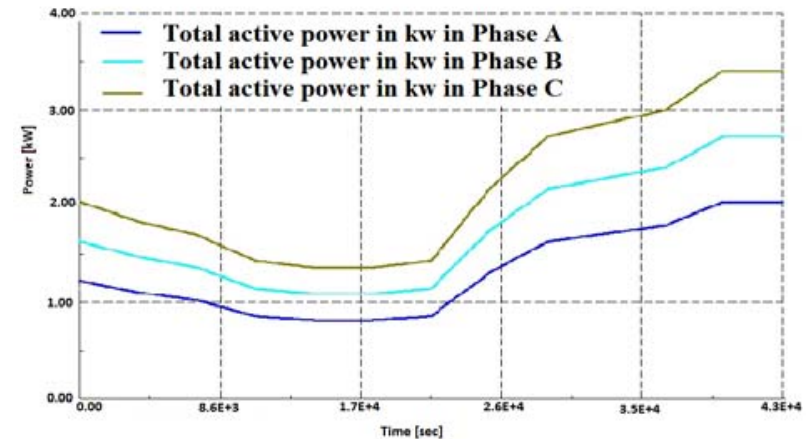

Fig. 15. Three phase unbalanced load at Bus D 


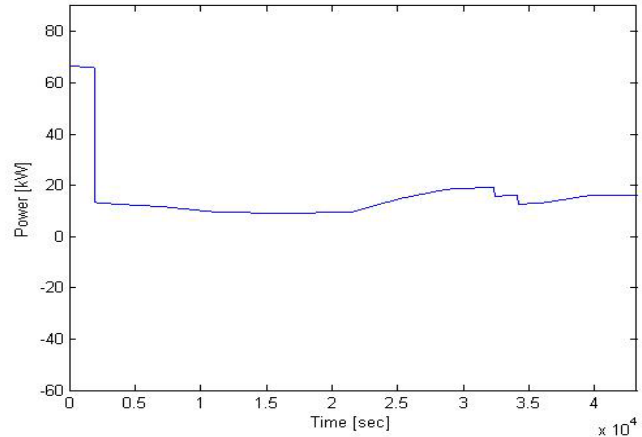

Fig.16. Power delivered by the grid

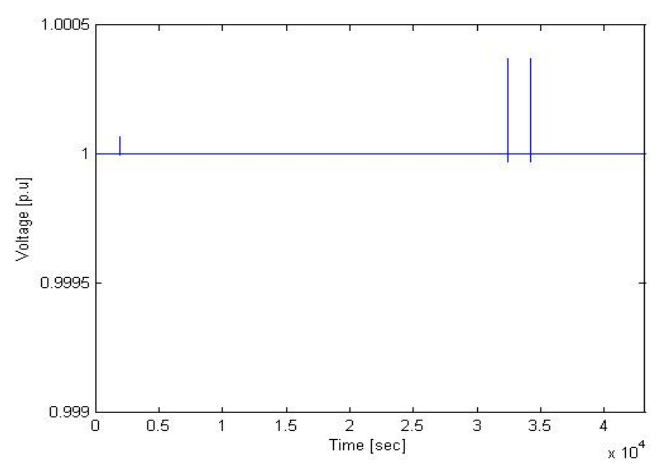

Fig.17. Voltage at bus D

The load demand is met by the WTG, PV system and the grid. The power delivered by the grid to meet the load demand and to charge the batteries is shown in Fig. 16. Initially the grid is delivering more power in order to charge the batteries and when both the batteries are fully charged it delivers less power as shown in Fig. 15.The fluctuations in the power delivered by the WTG, PV2 and the grid cause the problems with the network voltage. The fluctuations in the voltage are shown in Fig. 17. The first peak in the voltage is due to the power delivered by the grid to charge the batteries are minimized; the second and third peak is due the fluctuations in the power output of PV2. In all the cases control system is able to maintain the voltage in the desired range with very small and fast fluctuations.

\section{Conclusions}

The test network set up by the CIGRE comprising WTG, PVs, energy storages as well as unbalanced loads has been modeled in this paper. Because of small rating the WTG is modeled as a fixed pitch and fixed speed wind turbine. A new method of controlling PV solar system by using STATCOM controller has been proposed. It is shown in the simulation results that these controllers are successfully controlling the AC and the DC voltage during dynamic conditions. The BESS-STATCOM is also modeled and its controller is also developed. The battery controller is controlling the charge/discharge rate of the battery and has adequate control on the reactive power flow. In future these controllers will be tested in the transients and also in island conditions.

\section{Acknowledgements}

We are thankful to Kai Strunz for providing the CIGRE test network for LV distribution network. We are also thankful to DTU Wind Energy for providing wind speed data. I, Ghullam Mustafa am thankful to Quaid-E-Awam University of Engineering Sciences and Technology, Nawabshah, Sindh, Pakistan for their support and funding.

\section{References}

[1] Jenkins N. Impacts of dispersed generation on power systems. Electra, 2001; 199:6-13.

[2] Mahat P, Chen Z, Bak-Jensen B. Review of Islanding Detection Methods for Distributed Generation. China: Nanjing; 2008:69.

[3] International Energy Agency. (2010, July). Wind Energy 2009 Annual Report. [Online]. available: http://www.ieawind.org/AnnualReports_PDF/2009/2009AR_92210.pdf

[4] Farivar M, Clarkey CR, Low SH, Chandy KM. Inverter VAR control for distribution systems with renewables. Department of Electrical Engineering, California Institute of Technology Southern California Edison, Rosemead, CA, USA, Department of Computer Science, California Institute of Technology.

[5] Khadem SK, Basu M, Conlon MF. Power quality in grid connected renewable energy systems: role of custom power devices. In: Proc. of International conference on Renewable Energies and Custom Power Devices, ICREPQ'10, Spain: Granada; 2010: 23-25.. 
[6] Camacho EF, Samad T, Garcia-Sanz M, Hiskens I. Control for renewable energy and smart grids. In: Samad T, Annaswamy AM, editors. The Impact of Control Technology, 2011.

[7] Benchmark Systems for Network Integration of Renewable Energy Resources. Wersion 7. CIGRE Task force C6.04.02., 2011.

[8] Muyeen SM, Ali MH, Takahashi R, Murata T, Tamura J, Tomaki Y, Sakahara A, Sasano E. Comparative study on transient stability analysis of wind turbine generator system using different drive train models. IET Renewable Power Generation; 2007; 1(2):131-141.

[9] Santoso S, Le HT. Fundamental time-domain wind turbine models for wind power studies. Renewable Energy; 2007: 32(14): 2436-2452.

[10] Hansen AD, Iov F, Sørensen P, Cutululis N, Jauch C, Blaabjerg F. Dynamic wind turbine models in power system simulation tool DIgSILENT. Risø DTU, Denmark, Risø-R-1400(EN); 2007.

[11] Jetstream III Series-Grid Connected Turbine-IEC Class 1. [Online]. Available: http://www.sabletech.ie/Downloads/ wind\%20turbines.pdf

[12] Varma RK, Das B, Axente I, Vanderheide T. Optimal 24-hr utilization of a PV solar system as STATCOM (PV-STATCOM) in a distribution network. In: Proc. of Power and Energy Society General Meeting; 2011: 1-8.

[13] PV modelling by using DC current source, DIgSILENT Power Factory, Version 14.0 demo, DIgSILENT GmbH; Germany: Gomaringen.

[14] Bongiorno M. Control of voltage source converters for voltage dip mitigations for shunt and series configurations. PhD dissertation. Chalmers University of Technology; Sweden: Gothenburg; 2004.

[15] Du C. The Control of VSC-HVDC and Its Use for Large Industrial Power System. PhD dissertation. Chalmers University of Technology. Sweden, Gothenburg; 2007.

[16] Voltage control and stability of power systems in the presence of Distributed Generation. PhD dissertation. Division of Electric power Engineering, Department of Energy and Environment, Chalmers University of Technology. Sweden: Gothenburg; 2008.

[17] Harnefors L. Control of Variable-Speed Drives. V“aster as, Sweden: Applied Signal Processing and Control. Dept. of Electronics, M“alardalen University; 2002.

[18] Tremblay O, Dessaint LA, Dekkiche AI. A generic battery model for the dynamic simulation of hybrid electric vehicles. In: Proc. of Vehicle Power and Propulsion Conference, 2007:284-289

[19] Yao LW, Aziz JA. Modeling of lithium ion battery with nonlinear transfer resistance. In: Proc. of IEEE Applied Power Electronics Colloquium (IAPEC), 2011.

[20] Data sheet of Rechargeable Lithium-ion battery LiIon_Saft_VL_37570.pdf. [Online]. Available: www.saftbatteries.com

[21] Technical reference for DC voltage source in DIgSILENT. 